C O L A B O R A Ç $\tilde{A}$ O E S P E C I A L

\title{
TRAJETÓRIA ACADÊMICA, TEMPO PRESENTE E HISTÓRIA ORAL: CONVERSAS COM A HISTORIADORA ISMÊNIA DE LIMA MARTINS
}

Academic trajectory, present time and oral history: conversations with the historian Ismênia de Lima Martins

Trayectoria académica, tiempo presente y historia oral: conversaciones con la historiadora Ismênia de Lima Martins

\author{
ISMÊNIA DE LIMA MARTINS ${ }^{I^{*}}$ \\ ANA MARIA MAUAD ${ }^{* * *}$ \\ HEBE MATTOS ${ }^{1 * * *}$ \\ JUNIELE RABÊLO DE ALMEIDA ${ }^{\mathrm{I****}}$
}

https://doi.org/10.1590/\$2178-149420210309

\footnotetext{
'Laboratório de História Oral e Imagem, Universidade Federal Fluminense - Niterói (RJ), Brasil. *Doutora em História Social pela Universidade de São Paulo (ismeniadelimartins@gmail.com)

(D) https://orcid.org/0000-0001-9429-9477

**Doutora em História pela Universidade Federal Fluminense (anamauad@id.uff.br)

(D) https://orcid.org/0000-0002-6167-6712

*** Doutora em História pela Universidade Federal Fluminense (hebemattos@gmail.com)

(D) https://orcid.org/0000-0002-9158-2397

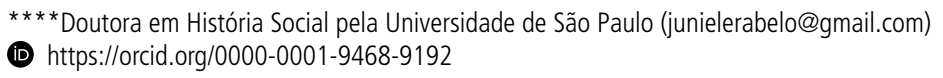

Artigo recebido em 15 de julho de 2021 e aprovado para publicação em 20 de julho de 2021. 
A

s conversas com a historiadora Ismênia de Lima Martins, ${ }^{1}$ professora emérita da Universidade Federal Fluminense (UFF), sobre a sua trajetória de vida acadêmica, foram iniciadas em agosto de 2012 e retomadas, de maneira remota por conta do cenário pandêmico, em junho de 2021. Os primeiros diálogos foram marcados pelas reflexões autobiográficas referentes à consolidação das pesquisas que entrecruzam história oral, o uso de fotografias na pesquisa história, estudos regionais e tempo presente no Brasil. Em meio às adversidades da COVID-19 e os problemas de saúde enfrentados pela professora Ismênia, as últimas conversas, ocorridas a distância, trouxeram o desejo de envolver: a sua experiência no processo de criação, em 1982, do Laboratório de História Oral e Imagem (LABHOI/UFF) e sua atuação no Programa de Pós-Graduação em História (PPGH/UFF), fundado em 1971; perpassando pelas memórias sensíveis da sua formação e pelos processos de transformação da pesquisa e ensino de História no Brasil.

A professora organizou generosamente a sua narrativa autobiográfica, autorizando a divulgação das gravações nos anos 2012 e 2021. Os dois arquivos audiovisuais, fruto desses diálogos, estão disponíveis para acesso no canal LABHOI/UFF do YouTube. As conversações que deram origem a esta publicação ultrapassam esses dois encontros, pois ocorreram com base na parceria consolidada entre Ismênia de Lima Martins e as entrevistadoras/mediadoras Ana Mauad, Hebe Mattos e Juniele Rabêlo — atualmente coordenadoras do LABHOI-Rede de Pesquisa.

Ismênia de Lima Martins graduou-se e obteve licenciatura em História, na UFF, durante o ano de 1967. Em 1973, doutorou-se em História Social pela Universidade de São Paulo (USP) e, no período de 1988 a 1990, participou do Programa de Pós-Doutorado pelo Comitê Francês de Avaliação da Cooperação Universitária com o Brasil (COFECUB), da Coordenação de Aperfeiçoamento de Pessoal de Nível Superior (CAPES), na École des Hautes Études en Sciences Sociales de Paris. Especialista em História do Brasil, no campo da História Social, trabalha principalmente com os temas relacionados à história fluminense, à imigração e ao gênero — atenta à interface memória social e tempo presente — campos que a levaram a se consagrar como fundadora do LABHOI/UFF, que é marcado por uma metodologia inovadora ao relacionar fontes orais e visuais na pesquisa histórica.

Ismênia foi Pesquisadora 1A do Conselho Nacional de Desenvolvimento Científico e Tecnológico (CNPq) de 1988 a 1996, é ex-presidente da Associação Nacional de Professores de História e ex-coordenadora de Editoração e Acervo da Fundação Carlos Chagas Filho de Amparo à Pesquisa do Estado do Rio de Janeiro (FAPERJ). Integrou o Conselho Nacional de Arquivos (CONARQ) e a Comissão de Altos Estudos do Programa Memórias Reveladas. Coordenou o Grupo de Trabalho "Imigração, Identidade e Cidadania" da Associação Nacional 
de História (ANPUH) e o Projeto Entrada de Imigrantes no Brasil, Arquivo Nacional-BNDES. Atualmente, compõe o corpo docente do Programa de Pós-Graduação em História da UFF, coordena o Núcleo de Estudos de Migrações, Identidades e Cidadania (NEMIC), integra a coordenação do projeto Portugueses no Brasil, em cooperação com o Centro de Estudos da População, Economia e Sociedade (CEPESE) e as Universidades Lusíada e do Porto, coordena os projetos Niterói de Todas as Gentes e Museu Digital das Migrações em Niterói e integra o projeto Cidadania, Turismo e Educação em Niterói, UFF/Prefeitura Municipal de Niterói.

\section{NARRATIVA AUTOBIOGRÁFICA DE ISMÊNIA DE LIMA MARTINS}

\section{SOBRE O MOMENTO ATUAL E AS MEMÓRIAS}

— m 2019 fiquei gravemente enferma, vários meses sem andar, dependendo de cuidados $\mathcal{L}$ dia e noite. Queria ficar bem para poder "curtir" meus dois bisnetos recém-nascidos, mas o que eu mais pensava era: "Será que eu vou ficar boa para poder dar aula de novo?". E hoje eu estou aqui com vocês, pronta para resistir. Que esses tempos de pandemia não abalem a nossa esperança, amar é fundamental e ter esperança também. Vale se entregar a esse ofício da história, a gente pode esperar felicidade nisso!

Bom mesmo é chegar aos 79 anos cercada pelo carinho, assistência, admiração dos nossos ex-alunos e até dos nossos colegas mais jovens. É a melhor coisa que poderia me acontecer profissionalmente. Imaginem que um grupo mais assíduo de colaboradoras se intitulam de "Ismenetes". Fico feliz com esse carinho! Também gosto do contato com os jovens colegas que trazem sangue novo!

Agradeço a oportunidade de falar sobre a minha trajetória profissional até chegar à atuação no programa de pós-graduação, considerando que fui a primeira professora doutora ex-aluna da UFF. Sempre me emociono quando repenso a minha história.

\section{O COLÉGIO INTERNO FRANCÊS NO RIO DE JANEIRO}

studei no Sacré-Coeur de Jesus, no Rio de Janeiro, que frequentei dos 13 até aos 18 anos, quan-
do completei o curso clássico. Era um colégio interno, mantido por uma ordem religiosa francesa dedicada a formar jovens da elite dotando-as de uma fina educação e não apenas formando-as como mães e esposas dedicadas. Algumas freiras eram muito eruditas. Estudei Filosofia, História, Literatura, Música e li Descartes pela primeira vez aos 15 anos! Vocês podem imaginar o impacto do Je Pense Donc Je Suis em uma jovem adolescente muito inquieta intelectualmente? 0 colégio católico disciplinou-me, impregnou-me de seus valores éticos, mas fez de mim uma filha do melhor racionalismo! 
Enfim, esse colégio foi para mim uma coisa maravilhosa, pois vinha de uma escola em Niterói, também de freiras, no caso espanholas, muito retrógradas, que sufocavam minha curiosidade intelectual com histórias de demônio e inferno.

\section{O ESTUDO UNIVERSITÁRIO E}

\section{A FAMÍlIA: DA PONTIFÍCIA UNIVERSIDADE CATÓlICA À UNIVERSIDADE FEDERAL FLUMINENSE}

m 1960, deixei o internato aos 18 anos, já noiva, e prestei vestibular para o curso de
Sociologia e Política na Pontifícia Universidade Católica do Rio de Janeiro (PUC-Rio), na época muito prestigiado academicamente. Lá vivenciei considerável crescimento teórico, tendo sido colega de Sérgio Lemos, Otávio Velho, Moacir Palmeira, entre outros. Casei-me em dezembro de 1961, e passados 19 meses já tinha dois filhos. Não havia pílula naquela época!

Na verdade, a universidade não era um projeto para as moças da família. Minhas duas irmãs casaram-se aos 19 anos, uma após concluir o curso clássico e a outra o normal. Minha mãe aceitou o meu ingresso em Sociologia e Política na PUC porque, como costumava dizer, eu era diferente e, sobretudo, o curso era de manhã.

No entanto, continuar o curso de Sociologia e Política na PUC-Rio era inconciliável com os meus encargos familiares. Residia em Niterói e a ida até lá levava quase duas horas, pois não havia ainda a ponte Rio-Niterói. Fiz novo vestibular na UFF, recém-criada, mas optei pelo curso de História, mais reconhecido e que tinha em seu corpo docente professores eruditos como o Francisco Falcon, que já conhecera na PUC. Passei em primeiro lugar, grávida do meu segundo filho.

Dessa vez, ao contrário do simples estranhamento, enfrentei grande resistência da minha família, sobretudo das mulheres: mãe, tia e avó que se preocupavam porque eu iria ficar "falada", pois o curso era noturno e eu uma mulher casada! Estudar para quê? Na verdade, fui criada para tocar piano, falar francês, declamar e casar cedo. Minhas irmãs seguiram o projeto familiar e eu casei-me para libertar-me. Se eu tivesse que dar um "título" para essa minha fala, eu chamaria de "vida, história e militância"!

\section{O CURSO DE HISTÓRIA DA UNIVERSIDADE FEDERAL FLUMINENSE: A CRÍTICA AOS REPETIDORES E A VALORIZAÇÃO DA HISTÓRIA DO TEMPO PRESENTE}

o curso de História, à época que o frequentei, não havia iniciação à pesquisa. Alguns
professores eram eruditos. Além da coleção da História Geral da Civilização e do Brasil, 
a primeira dirigida pelo Crouzet e a segunda por Sérgio Buarque, estudávamos história antiga, medieval, moderna e contemporânea nas grandes coleções Clio, Peuples et Civilisations, Évolution de L'Humanité, Cambridge History, bem como alguns clássicos portugueses e brasileiros. Mas não se estimulava o exercício da crítica e éramos todos, professores e alunos, repetidores, o que me parecia uma característica do meio universitário então, pois na própria Universidade Federal do Rio de Janeiro (UFRJ), como afirmou Eulália Lobo, reproduzia-se tal situação.

Enfatizava-se o factual, a história política e os conteúdos eram aprisionados por Cronos: "História era coisa do passado". Havia uma censura introjetada na Universidade pela ditadura militar, que já havia aposentado, compulsoriamente, muitos professores bem perto de nós, como na UFRJ as professoras Eulália e Maria Yedda Linhares. Estudava-se até a ditadura de Getúlio, mal chegávamos à Segunda Guerra Mundial e passava-se de forma quase impressionista por qualquer revolução, da francesa à russa! Enfim, não se estudava a História do tempo presente.

Esse princípio era tão arraigado que, em 1986, por ocasião da defesa de tese da Virgínia Fontes (Continuidades e rupturas na política habitacional brasileira, 1920-1979), em cuja banca participei, Maria Yedda Linhares, após os elogios sobre a pesquisa, declarou que 0 trabalho não era de História e sim de Sociologia porque era muito contemporâneo! A ocorrência evidencia que não se tratava de uma postura ideológica, pois, afinal, a professora era uma musa da esquerda brasileira. Fiquei muito constrangida, mas afirmei que História se definia pelo método e não por Cronos! Eu já conhecia o Institut d'Histoire du Temps Présent (IHTP), criado em 1978.

Na França, reproduzia-se a mesma situação. Entre 1988 e 1990, quando participei do Programa de Pós-Doutorado pelo COFECUB/CAPES na École des Hautes Études en Sciences Sociales de Paris, pude verificar que mesmo no meio acadêmico francês ainda havia resistência à História das últimas décadas, sem falar na reação frenética ao que se convencionou chamar História Imediata, como o caso da pesquisa da pesquisa jornalística sobre o caso Watergate.

\section{A DIMENSÃO DO SER SOCIAL: O INTERESSE POR UMA HISTÓRIA REGIONAL, DAS MULHERES E DOS OPRIMIDOS}

$\mathrm{O}$ s documentos são muito importantes para o trabalho do historiador e podem ser considerados a matéria-prima da História. Mas o mais importante são as questões que se colocam aos documentos. Na verdade, elas são o motor da História! E, como já dizia Marrou, as melhores questões nascem do entorno do historiador, das pressões sociais e econômicas e das relações que vivencia. Quer dizer, o historiador é um homem do seu tempo que, desfru- 
tando da liberdade criativa, pode transformar qualquer elemento do seu entorno, pertinente ao seu estudo, em fonte.

A dimensão do ser social que existe em cada um aguça sua sensibilidade para as melhores questões. Logo, percebi aquelas que me iriam estimular a vida inteira. A primeira delas brotou naturalmente das pressões que sofri como mulher, esposa e mãe, para me profissionalizar. Tornei-me uma militante e considero que o movimento feminista e a pesquisa se retroalimentam. Meu interesse particular foi estudar o lugar da mulher determinado socialmente e como conjunturas específicas favorecem a ação feminina na ruptura desses padrões.

Pelas minhas relações na cidade do Rio de Janeiro, vivenciei o desconforto de ser niteroiense. Sempre havia um ar de surpresa quando dizia que era de Niterói. Afinal, Sérgio Porto já proclamava que aqui era "a terra onde urubu voa de costas" e a melhor referência à cidade era de capital da velha província! Não me interessei pela questão do bairrismo e sim em pensar as especificidades regionais, particularmente de Niterói, articuladas a conjuntos maiores e sem ufanismo.

Desde menina sofri pela apreensão da pobreza e miséria no Brasil e no mundo. Nunca me comportei como uma riquinha! Na faculdade as preocupações com as pessoas e com a injustiça social me levaram a uma militância no campo socialista. Vivenciei, mesmo, as doenças infantis do esquerdismo e virei obreirista! Não aceitava a mesada que meu pai dava para todas as minhas irmãs e comecei a trabalhar dando aulas particulares e até de latim no pré-vestibular da PUC! Para além da militância, essas preocupações me levaram também a querer estudar a escravidão, o operariado e a imigração.

\section{DO SONHO DE SER PROFESSORA E HISTORIADORA À LUTA PELA PROFISSIONALIZAÇÃO}

uando me formei, em 1967, tinha muita expectativa em relação à minha profissiona-
lização. Não tinha dúvida de que queria ser uma professora! Durante o curso, além dos estágios obrigatórios no Instituto Abel, dera aula como substituta em São Gonçalo e continuava com as minhas aulas de reforço.

Mas eu estava certa de que ingressaria no ensino universitário na UFF. Àquela época, anterior à reforma universitária, não havia concursos públicos e o ingresso se dava pela indicação do catedrático e pela aprovação do nome no colegiado. Era um período de expansão do curso. Fui indicada para a vaga de Brasil, assim como três outros colegas para outras áreas, inclusive a Vânia Fróes para Medieval. Todos foram aprovados, menos eu! 0 professor Antônio Quaresma, que apresentou meu nome, informou-me da não aprovação e disse que, apesar do reconhecimento de minha inteligência e dedicação aos estudos, queixaram-se de 
que criticava demais os professores e não estava pronta para participar daquele coletivo. Além disso, de que a minha família era rica e eu ocupava uma vaga de quem precisava trabalhar! Fiquei muito abalada, mas, como sempre, reagi!

Candidatei-me a uma vaga de substituta do Liceu Nilo Peçanha, à época estabelecimento modelar do ensino público em Niterói. Com a volta da professora a quem substituíra, os alunos se rebelaram, exigiram minha permanência e o diretor renovou meu contrato. A minha experiência no segundo grau foi muito positiva, pois consolidou minha vocação para o magistério e amadureceu a minha experiência como educadora.

Deixei o Liceu apenas quando fui aprovada na primeira seleção pública do Departamento de História e nos quatro primeiros anos na UFF atuei na Faculdade de Economia, onde lecionava matérias obrigatórias de História Econômica 1 e 2.

Paralelamente às minhas atividades docentes, desde o tempo do Liceu, sistematizei esforços para iniciar-me como pesquisadora. Como já referi, anteriormente, o curso não estimulava a pesquisa. Sempre curiosa e atenta, li uma reportagem em jornal local sobre o trabalho de recolhimento de uma documentação provincial, identificada pela professora Thalita Casadei, nos porões da escola Aurelino Leal, antiga sede da Presidência da Província. 0 acervo foi transferido para a Biblioteca Pública do Estado, onde existia uma sala de documentação fluminense.

Quando aluna, manifestara ao professor Quaresma meu desejo de estudar a escravidão e ele me disse "Ruy Barbosa queimou tudo, você não vai ter fonte nenhuma". Na verdade, como bem mostrou Eduardo Silva, foram queimados, sobretudo, os documentos fazendários que poderiam respaldar as demandas de indenização dos senhores de escravos apresentadas ao governo republicano.

A professora Thalita me acolheu e pude conhecer e trabalhar a documentação interessando-me, particularmente, pelo conjunto referente à escravidão. Vivenciei pela primeira vez o prazer da pesquisa e já tinha algumas definições do que eu gostaria de fazer como historiadora. Não tinha dúvidas de que deveria dar continuidade aos meus estudos com a pós-graduação e, à época, o único programa existente no Brasil era na USP.

Mais uma vez vivenciei as dificuldades de profissionalização para as mulheres, esposas/mães nos anos 1960. Inicialmente a resistência da família de origem, porque meu marido sabia que era impossível me demover. Minha mãe, que me ajudava mesmo a contragosto, quando soube que eu ia fazer o doutorado em São Paulo, botou as mãos na cabeça e (com sotaque português) disse: "Meu Deus, agora, minha filha, é que tu vais ficar muito falada". Eu tive que vencer essa objeção da minha família e essa experiência provocou uma reflexão que sempre divulgo nos encontros feministas: que o machismo é uma questão social, de gênero e que muitas vezes as mulheres são repassadoras do machismo com mais força que os 
próprios homens. Meu pai era um médico muito famoso e tinha um encantamento pela vida intelectual, orgulho de mim e me incentivava discretamente para não desagradar a minha mãe. Chegou a propor que pagaria as passagens para São Paulo para que eu fosse acompanhada pela Dandaia, uma espécie de governanta da minha família. Já imaginaram eu chegar à USP acompanhada de Dandaia? Esse cruzamento da minha vida com os meus projetos de História foi sempre muito encaixado.

Mas não desisti, preparei meu projeto de pesquisa sem qualquer orientação e, por intermédio da professora Aidyl, consegui um encontro com a Alice Canabrava, historiadora muito importante e professora na Faculdade de Economia. Era a época da história quantitativa e eu, para me preparar, estudei complementos de matemática e estatística 1 e 2 no curso de Matemática da UFF. Meu projeto foi elogiado por ela, pois tratava do tráfico interno da província e eu trabaIhava com todo o movimento de escravos intraprovincial, buscando respostas à permanência da escravidão por mais de três décadas após a extinção oficial do tráfico. No entanto, a decepção foi grande, pois quando soube que eu não poderia ficar em tempo integral em São Paulo, mesmo com bolsa, pois era casada com dois filhos pequenos, disse que só aceitava orientandos naquela condição. As lágrimas vieram-me aos olhos e ela disse que eu não ficasse triste, que teria outras oportunidades e que iria me dar um presente: era um livro de receitas antigas!

Mais uma vez não desanimei e investi ainda mais alto. Consegui uma entrevista com o Sérgio Buarque de Holanda. Fiquei encantada, pois o Dr. Sérgio era uma alternativa, até então, inalcançável para mim. Acolheu-me com muita simpatia, não tanto pelo meu projeto, mas pela conversa que provocou sobre portugueses, literatura e conjuntura política. Infelizmente, aposentou-se logo depois, ainda em 1969, em solidariedade às aposentadorias compulsórias de vários professores da USP, entre eles a de Caio Prado, seu grande amigo. Passei, então, para a orientação de Nícia Vilela Luz, autora da primeira história da industrialização no Brasil, muito reconhecida. 0 curso de pós-graduação era de dois anos e, de acordo com o projeto, seria classificado para mestrado ou doutorado. Defendi minha tese em 1973, já docente da UFF como professora colaboradora.

\section{A CRIAÇÃO DE UM PROGRAMA DE PÓS-GRADUAÇÃO EM HisTÓRIA}

D estaco inicialmente a importância da USP no campo das Ciências Sociais no Brasil, e não apenas na História. 0 apoio da burguesia paulista garantiu recursos expressivos que custearam a permanência no Brasil de historiadores, geógrafos, sociólogos e antropólogos estrangeiros, sobretudo franceses e americanos, que formaram a primeira geração de 
cientistas sociais brasileiros, da qual fazia parte a Dra. Nícia. Posteriormente, na minha geração, recebeu profissionais de todo o país, preparando docentes e pesquisadores, que na década de 1970 sustentariam academicamente a expansão da pós-graduação ainda no período dos governos militares e que necessitavam de recursos humanos na área das Ciências Exatas e das Engenharias capazes de sustentar seus projetos desenvolvimentistas. Na verdade, 0 campo das Ciências Sociais não era alvo dessa política, mas com "engenho e arte", como diziam os cronistas portugueses, entramos no vácuo desse processo.

A criação do Mestrado da UFF em 1971 viabilizou-se graças ao prestígio e empenho da professora Aydil de Carvalho Preis, uma liberal que sempre protegeu os estudantes, mas que por seus talentos administrativos conquistou a respeitabilidade dos setores conservadores e do próprio sistema de informação da universidade.

Com habilidade inseriu nas discussões do Conselho Universitário, instância máxima de decisão da universidade, o debate em pauta na imprensa progressista, com denúncias sobre a compra de arquivos por instituições americanas e a relevância atribuída à produção dos brasilianistas americanos sobre a história do Brasil. Em uma reunião plenária, apresentou a revista Veja que trazia em sua capa o famoso quadro de Pedro Américo com a manchete "Independence or death". Discursou eloquentemente e concluiu: "Nós temos que escrever a História do Brasil no Brasil".

Os trâmites burocráticos transcorreram nos conselhos superiores e a maior dificuldade residiu na constituição do corpo docente, pois do quadro titulados éramos três: o Francisco Falcon, eu e a própria Aidyl. A primeira turma, diga-se, era de professores da própria UFF, o que foi um argumento importante para a criação do programa: qualificar seu próprio quadro. 0 curso começou com brasilianistas, dos quais o mais respeitado era o Richard Graham, havendo também a participação de brasileiros como José Honório Rodrigues e Pedro Ribeiro, este professor de América. A Dra. Nícia Villela teve participação destacada, pois montou um projeto sobre o recôncavo da Guanabara, dando origem a várias dissertações sobre a região.

0 programa destacou-se não apenas por ser o primeiro da área federal, mas por ocupar na área do Grande Rio um vazio criado pelas aposentadorias compulsórias da UFRJ, que afastaram de seus quadros os professores de maior visibilidade historiográfica.

0 grande salto qualitativo deu-se ainda na gestão da professora Aidyl, que teve vários mandatos sucessivos: primeiro, a renovação expressiva do Programa, trazendo Ciro Cardoso e Maria Yedda Linhares e Eulália Lobo antes de serem anistiadas. Dos brasilianistas ficaram Victor Valla e Robert Slenes. Segundo, com a implantação de um projeto de pesquisa que envolvia as diferentes áreas do programa. Nesse processo, recuperou-se a importância da pesquisa documental, que sustentou várias teses que deram origem a contribuições relevantes 
à historiografia regional e brasileira. Além disso, a perspectiva dos enfoques regionais, muito além dos ufanismos e das idealizações, buscava pensá-los em suas especificidades e como respostas a questões que se geravam nos quadros mais amplos, até do capitalismo mundial, da política nacional. Na verdade, até então, a história do Brasil era pensada por meio de grandes sínteses produzidas com base nas áreas hegemônicas, sobretudo São Paulo. É o caso, por exemplo, de Raízes da Concentração Industrial em São Paulo, de Wilson Cano, que afirmava que o Rio de Janeiro se caracterizava pelo investimento do capital na esfera da circulação e não da produção, como em São Paulo. Ana Maria Monteiro, minha orientanda, demonstrou exaustivamente que banqueiros e comerciantes foram os grandes investidores dos esforços industrializantes na Primeira República, ou seja, o livro, apesar de sua coerência interna, não correspondia à realidade concreta historicamente determinada do Rio de Janeiro. Muitos trabalhos de mestrado se tornaram referência historiográfica, como os de Gladys Sabina Ribeiro, Hebe Mattos, Sidney Chalhoub, entre outros. O Programa produziu também um conjunto de teses que afirmava que a decadência da lavoura cafeeira do Vale do Paraíba não provocou o empobrecimento da Velha Província em virtude das sucessivas frentes cafeeiras, como da região serrana e do noroeste fluminense, que tinham em Cantagalo e Itaperuna seus polos.

\section{O CENTRO de PESQuisa E DOCUMENTAÇÃo de HISTÓRIA CONTEMPORÂNEA DO BRASIL E O IMPACTO DO PRIMEIRO CURSO DE HISTÓRIA ORAL NO BRASIL}

primeiro curso de História Oral do Brasil ocorreu em 1975 e foi uma promoção do
Centro de Pesquisa e Documentação de História Contemporânea do Brasil (CPDOC), por iniciativa de Celina Vargas do Amaral Peixoto. Costumo dizer que Celina é uma mulher de grande espírito público. Sempre muito articulada, conseguiu organizar um convênio, captar recursos e trouxe professores estrangeiros para viabilizar o curso.

O programa teve formato de um curso intensivo de especialização de curta duração e havia representantes de diferentes instituições da área de documentação, de 33 universidades brasileiras, além de dois professores peruanos. Foi ministrado pelo casal de professores norte-americanos James e Edna Wilkie, da Universidade da Califórnia, e pela professora Eugenia Meyer, do Instituto Nacional de Antropologia do México. Eu representava a UFF. O corpo docente era muito eclético: o casal americano, muito pragmático, nos ensinava as técnicas da história oral, com o tom de quem dá uma receita de bolo; por outro lado, a historiadora mexicana Eugenia Meyer, profissional criativa e cheia de novas ideias, enfatizava todo o potencial 
político e social da história oral, não apenas para estudar as elites políticas, mas, sobretudo, para dar voz aos excluídos da história.

Para muitos participantes, os pressupostos teóricos e metodológicos da História Oral, que viriam a ser muito refinados até os anos 1990, eram desconhecidos. Mas o curso foi um estímulo para a criação de núcleos de história oral em várias universidades.

Fiquei muito marcada pelas propostas da história oral e logo incorporei essas preocupações às minhas atividades docentes. Os novos problemas, novos objetos, novos métodos eram muito lidos e eu provocava meus alunos questionando sobre como aplicar tudo aquilo. Meus cursos sobre industrialização ultrapassaram os padrões economicistas para verticalizar o social. Foi um período em que tive alunos muito especiais e eu incentivava ao máximo sua criatividade, os fiz comparar a letra francesa e a tradução que circulava no Brasil no início do século passado, que modificava versos e incluía uma estrofe inteira para atender às especificidades do anarcossindicalismo brasileiro.

Tenho um orgulho enorme de estar no memorial da tese de doutorado do Francisco Carlos Teixeira da Silva por ter ministrado o curso que mais marcou a sua pós-graduação. Quando trabalhava os números e estatísticas, eu dizia: "Para e pensa! Não são apenas números, são operários. É gente!".

Propus que os trabalhos de fim de curso articulassem as pesquisas historiográfica e documental com a de campo, utilizando a metodologia da história oral. A atividade deu origem ao primeiro conjunto de entrevistas com operários que trabalharam do início do século passado até 1930. Israel Beloch, por exemplo, fez uma entrevista maravilhosa com um senhor, funcionário da Santa Aleixo, que impactou a todos. Lembro-me que, tratando da disciplina na fábrica, o velho operário sentia-se tão à vontade que descreveu algumas práticas repressivas com detalhes, como aquela em que, para evitar que os funcionários demorassem muito tempo no banheiro, o que faziam muitas vezes para descansar, inventaram uma nova técnica que expelia do vaso "um vapor quente e queimava o 'traseiro' da gente!".

Para além de um detalhe tragicômico, da perversidade repressiva, outras questões do cotidiano ou de grande relevância poderiam ser apreendidas na voz dos excluídos, estimulando o homem comum a resgatar sua própria história. Enfim, era dar vida a Clio.

\section{O PRIMEIRO PROJETO DE PESQUISA COM FONTES ORAIS}

aria Amélia Migueis, documentarista do Museu Imperial, e Amélia Maria de Souza,
professora da UFF, conduziram um projeto sobre a historiografia petropolitana identificando um vazio no campo da história econômica. Convidaram-me, então, para coordenar 
um projeto sobre a história econômica de Petrópolis, cujo recorte seria de 1872 a 1930. A equipe contava com dois pesquisadores do museu, quatro professores da rede.

Petrópolis era conhecida como cidade imperial e de veraneio de elites do Rio de Janeiro, mas as primeiras sondagens indicavam a importância das manufaturas e das indústrias, com grandes unidades de produção de mais de mil operários já no início da Primeira República. Os registros oficiais sobre a economia local eram esparsos e exigiriam um esforço de pesquisa não compatível com o prazo previsto para a sua realização. Assim, propus que nos concentrássemos no setor de têxteis, uma vez que existiam não apenas registros regulares na imprensa local como, também, documentação das unidades de produção. Uma delas, a Petropolitana, tinha um arquivo completo com todos os relatórios de diretoria, folhas de pagamento, fichas, fotografias e até mostruários de tecidos.

Parte da equipe concentrou-se no fichamento dos relatórios e outra na documentação fabril. Em reuniões semanais discutíamos e eu problematizava criando sempre questões. Logo, identificamos claros documentais e eu propus um subprojeto de história oral que preencheria a ausência de informações sobre grupo étnico de origem, disciplina, horários, refeições, trabalho das crianças, multas etc., enfim, o cotidiano da fábrica. Os alunos da rede, sob a supervisão dos professores, aplicariam em sua vizinhança os questionários, curtos e objetivos, apenas para identificar os ex-operários, nossos futuros entrevistados.

Tivemos muito sucesso na pesquisa de campo. Eu mesma entrevistei seu Alberto, que em 1906 começou a trabalhar na Petropolitana, aos oito anos. Parti para a entrevista com um roteiro, mas logo entendi que o roteiro ideal em História Oral deve ser sempre aberto. Percebi, também, que os depoentes indicados pelo seu Alberto eram muito mais comunicativos do que os identificados pelas professoras e alunos. Afinal, o seu Alberto passou por muitas seções da fábrica e, quando se aposentou, era chefe da oficina. Então, quando eu dizia "foi o seu Alberto que me mandou aqui" eles se abriam para a entrevista.

Esse projeto resultou na publicação Subsídios Para Industrialização De Petrópolis e foi muito importante para mim, aprimorando-me na prática e orientação em história oral, estimulando-me no trabalhoso processo de criação formal e material do laboratório (regulamentação acadêmica, espaço e equipamentos).

\section{A CRIAÇÃO DO LABORATÓRIO DE HISTÓRIA ORAL E IMAGEM}

o início, quando funcionávamos no prédio do antigo Instituto de Arte e Comunicação
Social (IACS/UFF), tínhamos um armário de aço em cuja porta havia uma placa na qual se lia "Laboratório de História Oral". Fazia conferências citando as pesquisas, apresentando as 
entrevistas e, no encontro da ANPUH nacional, expus algumas fotografias da Petropolitana com trechos dos depoimentos. Fazíamos o laboratório acontecer! No prédio do campus Valonguinho, conseguimos uma pequena sala e depois, valendo-nos de uma conjuntura favorável, pois estava em curso o projeto Ministério da Educação/Banco Interamericano de Desenvolvimento (MEC/ BID) para a construção do campus do Gragoatá, incluímos no projeto do Instituto de Ciências Humanas e Filosofia (ICHF) o espaço que até hoje abriga o LABHOI. Apesar de todo o meu ânimo e vontade, o LABHOI só foi viabilizado, naquele período, graças ao apoio da professora Aidyl, que, além disso, nos conseguiu três bolsistas de excelente padrão que se tornaram professores na UFF, Eduardo Stotz na Fiocruz, Antônio de Oliveira Junior e Bernardo Koscher.

As necessidades materiais referentes aos equipamentos foram supridas pelo projeto Cidade e Campo no Complexo Regional, cuja montagem foi uma verdadeira epopeia uma vez que o Programa de Apoio ao Desenvolvimento Científico e Tecnológico (PADCT) excluía as Ciências Sociais. A Financiadora de Estudos e Projetos (FINEP), braço financiador do CNPq, que publicava editais com verbas vultosas, explicitamente não impedia que um projeto de História fosse apresentado. No entanto, tínhamos que preencher o formulário dos quais constava o seguinte item: "Aponte as maneiras de incorporação dos resultados do projeto aos setores produtivos da economia nacional".

Ainda que não se explicitasse no título, a ênfase do projeto recaía sobre o cotidiano e a classe operária. Como ligar o tema aos setores produtivos da economia? Era preciso não só dar nó em pingo d'água, mas nó em pingo de éter! E nós demos! A dona Yedda queria partir para o enfrentamento: "Isso é coisa de milico! Vamos dizer que o importante é a produção do conhecimento para as novas gerações". Eulália Lobo e eu concordamos, mas na verdade redigimos três páginas que detalhavam itens, mas cujo conteúdo, apesar da memória razoável para minha idade, não consigo lembrar porque era nonsense. É verdade que contávamos com o apoio das funcionárias da FINEP/Rio, simpatizantes do mesmo campo ideológico, inclusive a Madalena Diegues, que era mulher do Marcito Moreira Alves. Enfim, o projeto foi aprovado e viabilizou materialmente o LABHOI, além de garantir as bolsas de pesquisa.

Como o laboratório foi criado depois do projeto de Petrópolis, ele sempre teve "i". Como já referi anteriormente, entre a documentação preservada da Petropolitana encontramos muitas fotografias, destacando-se uma coleção de fotos, datadas do mesmo dia, que retratavam os funcionários organizados como em uma foto de estúdio. Havia uma hierarquia encenada: o contramestre estava ao lado, as crianças embaixo, sempre ladeadas por um adulto e, no primeiro plano, uma placa com o nome de cada seção. As fotos constituíram uma exposição por ocasião da assembleia geral daquele ano, cujo relatório mencionava uma greve "instigada por elementos estranhos ao nosso meio que foram expulsos e proibidos de pisar na Cascatinha". A pesquisa em jornais revelou a ocorrência de uma greve importante que se estendeu por todo o setor têxtil, permitindo, então, aprofundar a leitu- 
ra inicial que fizera daquelas imagens destinadas a registrar ordem, disciplina, controle e hierarquia. Outra questão que revelou a importância das imagens foi a da identificação dos setores em que trabalhavam as crianças da fábrica, pois os relatórios anuais explicitavam apenas o seu número. As fontes orais não traziam satisfatoriamente essa questão, visto que as respostas eram muito vagas e às vezes contraditórias. Enfim, desde meus primeiros trabalhos com História Oral, percebi a importância da imagem para a pesquisa e para o diálogo com a História Oral, justificando o "I" do LABHOI.

\section{A REESTRUTURAÇÃO DO LABORATÓRIO DE HISTÓRIA ORAL E IMAGEM E A ORGANIZAÇÃO DO CONGRESSO INTERNACIONAL DE HISTÓRIA ORAL}

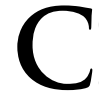

omeçamos muito bem, mas sofremos um roubo. Fui informada do ocorrido por dois alunos que mal conseguiam falar e gritavam: "Roubaram todos os nossos equipamentos!". Acalmei-os dizendo que recomeçaríamos, pois não levaram nosso coração, nossa cabeça e nossa vontade! Aí adentrou o Antônio Oliveira Júnior, mal contendo as lágrimas: "Professora... levaram as fitas também". Aí até eu dei uma baqueada! Levar equipamentos eram uma coisa, mas levar as fitas que nem serviam em nada para eles era demais!

Foi muito difícil reestruturar o Laboratório, pois na época eu acumulava muitas atividades e posições ligadas a minha militância no Movimento Feminista, como presidente no Centro da Mulher Brasileira de Niterói e no Movimento Docente, tendo sido primeira vice-presidente e segunda presidente da Associação dos Docentes da Universidade Federal Fluminense (ADUFF). Foi uma fase muito difícil, mas funcionamos ainda que com o pavio curto!

Quando Marieta Moraes, minha querida ex-orientanda, convidou-me para integrar a comissão por ela coordenada para a organização do Congresso Internacional de História Oral, declinei do convite impossibilitada pelo acumulo de tarefas da pró-reitoria que ocupava. Além disso eu integrava uma comissão ministerial encarregada de propor uma regulamentação para atividades extensionistas nas universidades federais, mas propus a indicação de Hebe Mattos como representante da UFF e comprometi-me a investir institucionalmente na realização do evento. A Hebe e o Paulo Knauss, que tinham ministrado o primeiro curso deles de História Oral na graduação em conjunto comigo, assumiram o laboratório atraindo também a Marisa Carvalho e Ana Mauad. Daí para frente, foi uma história de sucessos que todos conhecem bem. Depois da pró-reitoria, dirigi o Arquivo Público do Estado, fui coordenadora da FAPERJ e presidente da Associação Cultural do Arquivo Nacional e mantive poucas atividades no LABHOI, mas sempre estive no seu entorno. 


\section{RETOMADA DAS ATIVIDADES ACADÊMICAS, AMOR E MILITÂNCIA}

o tempo em que estive doente e impossibilitada de me locomover, de ler, só podia pen-
sar e refleti muito sobre minha vida. Como Piaf, je ne regrette rien — eu não me arrependo de nada e estou contente comigo porque o que fiz melhor na minha vida foi por amor.

Essa minha relação consciente com o amor é muito antiga. Fui oradora da minha turma de clássico do colégio francês, e era costume colocar no convite uma epígrafe. Escolhi uma expressão em latim: ama et fac quod vis - ama e faz o que queres. A madre responsável não gostou porque considerou que aquilo era muito profano. Eu retruquei que era Santo Agostinho, mas ela não se convenceu e fomos falar com a madre superiora, que me apoiou, mas, para evitar um conflito com a outra, resolveu recorrer ao capelão, um erudito austríaco e membro do Instituto Histórico e Geográfico Brasileiro (IHGB), como soube mais tarde. Finalmente eu consegui manter a epígrafe. Foi o lema da minha vida. Amo a História e se não a amasse não seria historiadora, como dizia Lucien Febvre. Mas amo igualmente ser professora. Me interesso por cada um dos meus alunos e não quero apenas ministrar-lhes o ensino formal, quero educá-los para o exercício de uma cidadania comprometida com a democracia e a justiça social. Nós profissionais da educação temos que pensar não apenas em nos realizarmos intelectualmente, mas, também, em nossos compromissos sociais. Uma história engajada não é uma história subordinada, não é uma história servil. É uma história militante que nos ensinaram grandes historiadores como Marc Bloch e muitos outros.

Mas há também a militância pelo nosso ofício, que se exerce na sala de aula, no estúdio de pesquisa, na universidade, no ensino fundamental e médio, produzindo e repassando conhecimentos aos nossos alunos e estimulando a reflexão crítica. Todo o tempo em que fui professora regular do quadro do departamento de História, sempre mantive atividades extensionistas no ensino básico da rede pública e gosto de dar aulas não apenas na pós mas, também, na graduação. Nesse processo sempre me revigorei com as demandas externas da universidade e as das novas gerações de estudantes.

Estou feliz de participar do movimento de historiadores que reconhecem o valor da participação social na construção de uma História Pública. Disse para Juniele Rabêlo, minha querida colega, que integrou várias comissões administrativas/científicas da Rede Brasileira de História Pública, que aos 79 anos (em 2021) já assisti a muitas inovações teórico-metodológicas no campo historiográfico, mas que tenho uma satisfação enorme em saber que já fazia História Pública antes que lhe conferissem um status acadêmico. 


\section{TRABALHO, REALIZAÇÃO PESSOAL E O INESPERADO!}

$\mathrm{T}$

rabalhar não é apenas uma maneira de ganhar a vida, mas também de realização pessoal. Fiquei muito feliz quando a partir de janeiro fui retomando minhas atividades acadêmicas e docentes. $E$, aí, o inesperado acontece mais de um século depois das descobertas de Pasteur: o Brasil e o mundo são atingidos por uma pandemia que deixa a todos perplexos pelas dificuldades de controle do vírus em uma sociedade que acumula tanto conhecimento tecnológico e científico, que cria a inteligência artificial, a robótica e que se lança à conquista de outros mundos!

Na primeira fase, não senti o peso da pandemia. Vendo a estatística, eu ficava aflita por causa do povo brasileiro, do desgoverno, pela precariedade da rede de saúde, pelo aumento da pobreza e da violência, mas na verdade a minha atenção e a pouca energia que eu tinha era absorvida na minha luta pela sobrevivência. E o inesperado foi que, quando melhorei e cada vez mais tive essa pulsão de vida, fui reprimida pelo isolamento forçado. Foi muito duro!

Quando fui acometida pela primeira doença grave, uma mielodisplasia, eu que sempre busquei ser positiva afirmava que a doença tivera até uma coisa boa, porque me fizera tomar consciência de meus limites. Coisa que 15 anos de psicanálise não tinham conseguido! Depois tive outros problemas de saúde que acabaram me deixando dependente de uma máquina de diálise. Quando superei a fase mais grave, consegui estabilizar esse processo e pude retomar minhas atividades profissionais, veio a pandemia. É demais! Não dá para brincar de contente!

Agravando esse quadro, tem a pandemônia: o descrédito e a fragilidade das instituições políticas, a insegurança em relação aos direitos do cidadão, as ameaças à democracia, o crescimento da violência, a ausência de lideranças políticas e sobretudo a corrupção no momento de uma tragédia humanitária que já matou mais de meio milhão de brasileiros, 0 atraso na viabilização da compra de vacinas, a desmobilização contra o desgoverno e essa incapacidade da esquerda de se articular com os liberais progressistas, enfim, eu tudo vejo com muita tristeza.

Quanto à universidade, fiquei surpreendida pelo esforço dos meus colegas em manterem, além das atividades didáticas e administrativas dentro do nível exigido, um conjunto expressivo de atividades na área de pesquisa. Por outro lado, achei frágil a presença política contra o desgoverno. É preciso manter a esperança e resistir. Mas a esperança não pode ser passiva. Quem sabe faz a hora! 
Conflitos de interesse: nada a declarar.

Fonte de financiamento: Programa Institucional de Internacionalização, Coordenação de Aperfeiçoamento de Pessoal de Nível Superior (PRINT/CAPES).

Contribuições das autoras: MARTINS, I. L.: Escrita — Revisão, Validação e Visualização. MAUAD, A. M.: Escrita — Revisão; Recursos. MATTOS, H.: Recursos; Supervisão. ALMEIDA, J. R.: Coordenaçãa do projeto, Escrita — Revisão e Edição.

\section{NOTA}

1 Destacam-se, na diversificada produção bibliográfica da professora Ismênia de Lima Martins, as seguintes publicações: Martins (1983, 1995); Martins e Knauss (1997); Sousa, Martins e Matos (2009); Martins e Engel (2011); Martins e Hecker (2013); Martins, Rocha, Moraes e Gontijo (2016).

\section{REFERÊNCIAS BIBLIOGRÁFICAS}

FONTES, V. M. G. de M. Continuidades e rupturas na política habitacional brasileira: 1920-1979. 1986. 277 f. Dissertação (Mestrado em História) - Universidade Federal Fluminense, Niterói, 1986.

MARTINS, I. L. Subsídios para a história da industrialização em Petrópolis. Petrópolis: PUC, 1983.

MARTINS, I. L. Anotações sobre a História do Trabalho no Brasil. Revista Brasileira de História, São Paulo, v. $X V$, n. 30, p. 91-100, 1995.

MARTINS, I. L.; ENGEL, M. Mujeres doctoras en el Brasil: estudio de caso. In: ACCORSI, S.; VALCKE, C.; BETANCOURT, G. (orgs.). Meridiano género: cultura y sociedade. Cali: Universidad del Valle, 2011. v. 1, p. 153-182.

MARTINS, I. L.; HECKER, A. (orgs.). E/Imigrações: questões e inquietações. São Paulo: Expressão \& Arte, 2013.

MARTINS, I. L.; KNAUSS, P. Cidade múltipla: temas de história de Niterói. Niterói: Niterói Livros, 1997.

MARTINS, I. L.; ROCHA, H. A. B.; MORAES, L. E. S.; GONTIJO, R. Identidades, memórias e projetos políticos. Rio de Janeiro: FGV, 2016.

MAUAD, A. M. Usos do passado e História pública no Brasil: a trajetória do Laboratório de História Oral e Imagem da Universidade Federal Fluminense (1982-2017). História Crítica, Bogotá, v. 68, p. 27-45, 2018. https://doi.org/10.7440/histcrit68.2018.02.

SOUSA, F; MARTINS, I. L.; MATOS, M. I. (orgs.). Nas duas margens: os portugueses no Brasil. Porto: Afrontamento, 2009. 